\title{
Características discursivas de textos da revista Minas Faz Ciência e suas potencialidades no ensino de química
}

\author{
Discursive characteristics of texts from Minas Faz Ciência magazine and their \\ potential in chemistry education
}

\begin{abstract}
Marcio César Braga Batistele (iD https://orcid.org/0000-0001-6738-4182 Pós-graduação em Ensino de Ciências, Universidade Federal de Itajubá e-mail - marcio.batistele@bol.com.br

Jane Raquel Silva de Oliveira (iD https://orcid.org/0000-0002-7891-5820 Instituto de Física e Química, Universidade Federal de Itajubá e-mail - janeraquel@unifei.edu.br
\end{abstract}

\section{Resumo}

O objetivo desta pesquisa foi analisar algumas características discursivas didáticas, laicas e científicas presentes em textos da Minas Faz Ciência, uma revista produzida pela Fundação de Amparo à Pesquisa do Estado de Minas Gerais (FAPEMIG). Foram selecionados para este estudo dez textos dessa revista com temas relacionados ao currículo de Química, tais como água, meio ambiente, energia etc. Os textos foram analisados por meio da metodologia de Análise Textual Discursiva, usando como referencial teórico características do discurso da divulgação científica. Foi observada nos textos a predominância dos aspectos didáticos e laicos, devido à presença de características como: procedimentos explicativos, recuperação de conhecimentos tácitos, temáticas e abordagens contextualizadas, linguagem acessível e recursos visuais atrativos. Também foram observados alguns aspectos relacionados ao funcionamento da atividade científica e uso do argumento da autoridade.

Palavras-chave: Discurso científico. Texto de divulgação científica. Ensino de química.

\begin{abstract}
This work presents a analyze about didactic, lay and scientific discursive characteristics present in texts from Minas Faz Ciência, a magazine for popularization of science published by the Foundation for Research Support of the State of Minas Gerais, Brazil. For this study, ten texts from this magazine were selected, covering topics related with Chemistry curriculum, such as water, environment, energy, etc. The texts were analyzed through the Discursive Textual Analysis methodology, using as theoretical reference the discourse characteristics
\end{abstract}


of popularization of science. It was observed in these texts didactic and laic aspects predominance, due to the characteristics such as: explanatory procedures, a recovery knowledge tacit, contextualized thematic, accessible language and attractive visual resource. Some aspects related to the scientific activity and arguments used by authority were also observed.

Keywords: Scientific discourse. Popular scientific texts. Chemistry education.

\title{
Introdução
}

Em uma sociedade fortemente baseada na ciência e tecnologia, a divulgação científica (DC), realizada em diferentes contextos e por meio de vários suportes e ações, tem implicações sociopolíticas importantes. Segundo Gouvêa (2015, p.15), para os não praticantes da ciência e da tecnologia (população em geral),

ter acesso aos conhecimentos científicos e tecnológicos significa, principalmente, poder discutir e interferir na decisão de políticas púbicas para o sistema da ciência e da tecnologia, o que caracteriza estes não praticantes como alfabetizados científica e tecnologicamente.

Albagli (1996) destaca que a DC vem evoluindo ao longo dos anos e pode se orientar a objetivos educacionais (para ampliação do conhecimento científico da população) e cívicos (para desenvolvimento de opinião pública informada sobre implicações do desenvolvimento científico e tecnológico sobre a sociedade).

Além do papel social e político da DC, seus recursos e espaços têm estabelecidos profundas relações com a educação formal. É caso, por exemplo, dos textos de divulgação científica (TDC), comumente usados na educação em ciências como aliado ou material alternativo ao uso do livro didático. "Em geral a inclusão desses textos tem como intuito preencher a falta de materiais atualizados em Ciência e Tecnologia ou a substituição de materiais por algo mais acessível aos estudantes em termos de linguagem" (CUNHA; GIORDAN, 2015, p.73).

Algumas características dos TDC favorecem seu uso no contexto escolar. Segundo Almeida (2010, p.21),

\begin{abstract}
grande parte deles apresenta uma linguagem razoavelmente próxima à linguagem de quem frequenta a escola, à linguagem cotidiana do estudante; em muitos deles a linguagem se aproxima da linguagem literária, ainda que parcialmente; muitos incluem textos em quadrinhos e/ou comentários humorísticos; de muitos deles fazem parte aspectos da biografia dos cientistas que produziram os conhecimentos a que estão se referindo e/ou fatos históricos associados à produção daqueles conhecimentos; outros incluem não só o conhecimento em si e aspectos da sua produção, mas também algumas de suas consequências para a sociedade, ou mesmo apontam quais fatos sociais contribuíram para a produção do conhecimento científico a que se referem.
\end{abstract}

Benefícios do uso de TDC na sala de aula são apontados por vários autores, dentre os quais se destacam: a inserção de temas atuais e ligados ao cotidiano dos alunos, o favorecimento da aprendizagem de conceitos científicos, o desenvolvimento de habilidades de leitura, a melhoria da capacidade de argumentação, a formação de leitores críticos etc. (GABANA; LUNARDI; TERRAZZAN, 2003; MARTINS; NASCIMENTO; ABREU, 2004; SILVA; ALMEIDA, 2005). A introdução de TDC em sala de aula pode ainda contribuir para que a população faça imagem crítica da ciência e possa discutir suas aplicações 
tecnológicas presentes no cotidiano e na sociedade de um modo geral (CHAVES; MEZZOMO; TERRAZZAN, 2001).

Nessa perspectiva, conforme Ferreira e Queiroz (2012), várias pesquisas têm sido realizadas na área de ensino de ciências voltadas à análise de revistas de DC, com o intuito de colocar em destaque elementos que auxiliem os professores na escolha mais adequada de materiais dessa natureza para uso no contexto educacional. Embora a maioria dos trabalhos indiquem os possíveis benefícios do uso de TDC em ambientes de ensino, muitos também apontam uma série de condicionantes.

\begin{abstract}
A função primordial da abrangência dos TDC não consiste em fantasiar os conceitos ou fenômenos, ou apenas motivar a curiosidade dos alunos, mas de recuperar significados mais amplos e diversificados para o ensino;[...] tendo em vista estabelecer as necessárias relações entre ciência, tecnologia e sociedade, deverá ser tomado o cuidado em selecionar o material pertinente à realidade escolar, e não fatos sensacionalistas, de modo que resulte em um trabalho interdisciplinar e atrativo para os estudantes (FERREIRA; QUEIROZ, 2012, p.15).
\end{abstract}

Dentre os TDC mais analisados nessas pesquisas, destacam-se revistas como Ciência Hoje, Superinteressante e Scientific American. Além dessas mais conhecidas do grande público, há alguns poucos estudos também envolvendo revistas de DC produzidas por fundações de apoio à pesquisa, como a revista Pesquisa FAPESP, publicada pela Fundação de Amparo à Pesquisa no Estado de São Paulo, (FERREIRA; QUEIROZ, 2012).

O estudo realizado por Mota, Gontijo e Oliveira (2017, p.979) revelou que TDC da revista Pesquisa FAPESP "podem ser úteis como recurso didático ao ensino sobre ciência, uma vez que possibilitam discutir em sala de aula aspectos importantes do modo como a ciência é atualmente construída, bem como ressaltar facetas do trabalho do pesquisador raramente presentes na imagem que as pessoas têm sobre ser cientista". Tal aspecto deve-se, em parte, ao fato de que revistas dessa natureza costumam apresentar em suas reportagens os "quens", "ondes" e "porquês" relativos às pesquisas que relatam (FOSSEY, 2007). Portanto, a literatura vem evidenciando, aos poucos, o potencial didático para educação em ciências de TDC produzidos pelas agências públicas de apoio à pesquisa.

Outra importante revista de DC dessa natureza é Minas Faz Ciência, publicada pela Fundação de Amparo à Pesquisa no Estado de Minas Gerais (FAPEMIG). A revista, que circula desde dezembro de 1999, tem como alvo o público não especializado, utiliza uma linguagem acessível e se preocupa em discutir avanços, descobertas, implicações e controvérsias da Ciência, Tecnologia e Inovação, visando contribuir para o fortalecimento de uma cultura científica do país (FAPEMIG, 2018).

Alguns poucos trabalhos na literatura têm adotado essa revista como objeto de estudo. Em um deles, Ocáriz (2013) realizou a análise da seção Carta do Leitor com intuito de verificar qual a relação das publicações da revista com seu leitor. Conforme a autora, o público principal da revista é composto por estudantes e acadêmicos, considerados como leigos, uma vez que não se encontram necessariamente inseridos nas pesquisas científicas.

A pesquisa de Gontijo e Oliveira (2019) apresentou uma análise dessa revista na perspectiva da sociologia da ciência, buscando identificar elementos que evidenciassem o cotidiano da ciência e do cientista. Segundo as autoras, alguns 
textos da Minas Faz Ciência possibilitam evidenciar aspectos como: a colaboração entre instituições, sejam elas públicas ou privadas; a importância das alianças com outros pesquisadores para a articulação de conhecimentos e técnicas, bem como o fortalecimento da rede científica; o uso de estratégias da persuasão; a preocupação dos cientistas com a obtenção e o gerenciamento de recursos materiais e humanos para a pesquisa; a valorização de publicações, entre muitos outros aspectos que constituem o fazer ciência e o cotidiano do cientista.

Esses estudos, no entanto, não exploram outras possíveis potencialidades dos TDC, como, por exemplo, a presença de elementos didáticos ou conteúdos relacionados ao cotidiano do leitor - aspectos que também favorecem o uso desse tipo de recurso no contexto escolar.

Dessa forma, o objetivo deste trabalho foi analisar textos da revista Minas Faz Ciência com temas relacionados à química, identificando de forma específica nesses materiais seus elementos didáticos, laicos e científicos. Com essa análise, buscamos trazer à literatura da área de ensino de ciências, algumas discussões sobre características desse recurso da DC e suas potencialidades para o ensino de química.

\title{
O discurso da divulgação científica
}

Um dos aspectos centrais na construção e difusão da ciência é a publicação de textos científicos, os quais constituem um discurso próprio compartilhado e constantemente avaliado pelos membros da comunidade científica (LATOUR; WOOLGAR, 1997). Conforme Targino (2007, p.21),

\begin{abstract}
a produção científica prima por um padrão léxico, em que as nominalizações e os termos ou jargões técnicos, acessíveis só aos especialistas, prevalecem. Apresenta, ainda, estas características: (1) emprego usual da $3^{a}$ pessoa do singular (que, acrescida da partícula se, evidencia indeterminação do sujeito) ou da $1^{\text {a }}$ pessoa do plural (sujeito universal); (2) concisão ou economia linguística; (3) precisão ou cuidado máximo com ambiguidades; (4) objetividade ou rejeição a traços inerentes à linguagem afetiva, pautada pela expressão de sentimentos, que o autor vivencia ou que deseja provocar no ânimo do interlocutor; (5) formalismo ou exclusão de termos do dia-a-dia ou de uso vulgar.
\end{abstract}

Bueno (2010) estabelece algumas diferenças entre a linguagem presente na comunicação científica (entre os pares) e aquelas características da DC (para o grande público). A comunicação científica não necessita de uma decodificação do discurso especializado, uma vez que, implicitamente, acredita-se que seu público compartilhe os mesmos conceitos e que o jargão técnico seja um patrimônio comum. Na DC, por sua vez, a difusão de informações científicas e tecnológicas para o público considerado leigo "requer decodificação ou recodificação do discurso especializado, com a utilização de recursos (metáforas, ilustrações ou infográficos etc.) que podem penalizar a precisão das informações" (BUENO, 2010 , p.3). O autor chama atenção ainda para o embate dentro da produção do discurso da DC: por um lado a necessidade de manter a integridade dos termos técnicos e conceitos no intuito de se evitar leituras equivocadas; por outro, a importância de que a comunicação seja estabelecida de forma efetiva, respeitando-se o background sociocultural ou linguístico da audiência. 
Segundo Zamboni (2001), considerando o discurso científico presente entre os pares como o discurso-fonte, uma das correntes teóricas na área de linguística entende a atividade de DC como uma prática de reformulação textual-discursiva do discurso científico, na qual são adotadas estratégias como tradução, resumo, paráfrases e outras práticas no sentido adaptar o conteúdo científico para um determinado nível de audiência.

A autora, no entanto, contrapõe-se a essa ideia e vê "na divulgação muito mais o trabalho de formulação de um novo discurso, que se articula, sim, com o campo científico - e o faz sob variadas formas - mas que não emerge dessa interferência como o produto de uma mera reformulação de linguagem" (ZAMBONI, 2001, p.xvii). Assim, ela estabelece que esses textos são gêneros diferentes que tratam do mesmo assunto, mas apresentam construções textuais e estilos de linguagem diversos. A diferença entre as formas de comunicação científica se baseia na mudança do destinatário, ou seja, do público alvo, que passa a ser agora um público aberto, tido como leigo em matéria de ciência ou em determinada especialidade.

\begin{abstract}
Se é constitutivo do discurso estar voltado para o destinatário, e se esse destinatário se concebe diferentemente em diferentes condições de produção, tal como ocorre com os destinatários do discurso científico e com os do discurso da divulgação científica, é lícito concluirmos que estamos diante de dois gêneros discursivos (ZAMBONI, 2001, p. 94).
\end{abstract}

Zamboni descreve uma série de características inerentes ao discurso da DC, tais como:

a) Procedimentos explicativos. São segmentos explicativos dirigidos a receptores não especialistas, a quem pode faltar o domínio de conhecimentos prévios e de conceitos referentes ao assunto do artigo proposto. Envolvem definições e explicações realizadas sobretudo por meio de inserções parentéticas e apositivas.

b) Interlocução direta com o leitor. Podem aparecer na forma de perguntas apreciativas, buscando-se a participação ativa do leitor. O destinatário é interpelado, de forma a ser convidado a participar das discussões acerca do tema abordado no texto.

c) Recuperação de conhecimentos tácitos. Os conhecimentos tácitos seriam aqueles sobre os quais não cabe mais apresentar comprovação ou contestação, isto é, termos ou expressões tão aceitos na área que não necessitam mais de explicações. No entanto, o discurso da divulgação científica recorre à recuperação de tais conhecimentos para um público mais leigo.

d) Recurso à atratividade. São estratégias discursivas para tornar a matéria atraente. Dentre os recursos dessa natureza destacam-se: as narrativas de envolvimento para manter o leitor interessado na matéria (menção a personagens ilustres ligados, dados estatísticos etc.); boxes (quadros com linhas, faixas, fundos coloridos, que trazem conteúdos específicos e títulos próprios); mini resenhas (geralmente no máximo três linhas, com conteúdo que instigue o leitor a prosseguir com o texto).

e) Segmentação da informação. Segmentação em partes de leitura independentes, permitindo a leitura por partes isoladas. 
f) Apelo inicial à leitura. É a tentativa de prender o leitor à matéria. Esse apelo é realizado, geralmente, por meio de impacto visual da reportagem, informação chamativa etc.

g) Impacto científico no lide. Em poucas linhas o essencial do texto, comumente presente no primeiro parágrafo do texto, juntamente com o título, constituem o sumário da notícia.

h) Questionamento sobre a metodologia empregada na pesquisa. Quando o autor questiona 0 alcance da descoberta em relação ao processo metodológico da pesquisa, e por vezes indica sugestões.

i) Atitude de cautela e prudência diante dos resultados da pesquisa. A presença desse tipo de procedimento pode ser interpretada no discurso da DC como enunciação dirigida a um público mais restrito e com certo grau de especialização. Evidencia a provisoriedade das "descobertas".

j) Busca de credibilidade. Presente por meio de falas de especialistas, conferindo ao discurso da divulgação científica certo grau de autoridade.

Zamboni (2001, p.96) aponta ainda que no discurso da divulgação científica pode ser observada a "superposição de traços de cientificidade, laicidade e didaticidade, que se deixam mostrar, em graus variados, na superfície dos textos". Queiroz e Ferreira $(2013,950)$, tomando como base as definições de Zamboni, consideram que

os traços de cientificidade são aqueles típicos do discurso científico. No entanto, nos TDC, esses traços revelam não apenas aspectos explícitos da práxis científica, mas, também, implícitos (como características pessoais de cientistas, consequências negativas de certos produtos de ciência, entre outros). Ou seja, são marcas de estratégias enunciativas pressupondo um leitor que busca compreender as pesquisas científicas que envolvem a temática do TDC, entender como a ciência é praticada, suas finalidades, a demanda de pesquisas científicas, entre outros. Os traços de laicidade compreendem elementos inerentes ao discurso cotidiano, os quais abarcam as várias formas de contextualização. Traços dessa natureza são evidenciados por meio de recursos discursivos que envolvem a relação da temática científica tratada no TDC com o cotidiano do leitor, portanto, incluem procedimentos de aproximação, simplificação, exemplificação, fórmulas de envolvimento, entre outros. Os traços de didaticidade são próprios do discurso didático, os quais incluem procedimentos como explicações, recapitulações e orientações metodológicas. Neste caso, o enunciador pressupõe um leitor que necessita adquirir certo saber para dar cabo da leitura. Logo, aciona uma série de estratégias com o objetivo de favorecer o entendimento de seu destinatário sobre os aspectos científicos tratados no TDC (grifo nosso).

Consideramos que, de forma geral, por meio da caracterização dos TDC publicados em diferentes veículos, é possível identificar algumas de suas potencialidades como recurso didático, possibilitando aos professores utilizá-los adequadamente de acordo com seus objetivos.

\section{Percurso metodológico}

A revista de DC Minas Faz Ciência é uma publicação da FAPEMIG que surgiu como uma iniciativa da agência para propiciar a democratização do conhecimento por meio da divulgação de pesquisas científicas, mais especificamente aquelas 
desenvolvidas no estado de Minas Gerais. Inicialmente, foi criado o projeto Minas Faz Ciência, que abrangia uma série de vídeos produzidos pela Rede Minas. Posteriormente foi criada a revista Minas Faz Ciência, em dezembro de 1999, com uma tiragem inicial de cinco mil exemplares, tendo como alvo o público não especialista. Sua publicação é trimestral, de distribuição gratuita e com tiragem atual de aproximadamente 20 mil exemplares. A revista possui mais de seis mil assinantes espalhados por todos os estados e em oito países, tendo leitores das mais variadas idades e profissões. Além disso, em 2000 surgiu sua versão online também gratuita (FAPEMIG, 2018).

Para análise dos TDC da revista Minas Faz Ciência delimitamos um corpus de dez textos, dentre aqueles que compõem as reportagens sobre pesquisa científica, publicados entre 2010 e 2015. Tais textos, codificados de A a J, estão listados no Quadro 1.

A fim de possibilitar uma discussão sobre as potencialidades dessa revista para o ensino de química, foram prioritariamente selecionados textos cujas reportagens contemplassem temas relacionados à química e áreas afins. Além disso, estes TDC deveriam abordar questões diversas sobre a ciência, incluindo seus aspectos conceituais, tecnológicos, sociais, econômicos, ambientais etc.

Quadro 1 - Textos selecionados da revista Minas Faz Ciência.

\begin{tabular}{|c|c|c|c|c|}
\hline Texto & Título & Autor & Volume & $\begin{array}{c}\text { Ano de } \\
\text { publicação }\end{array}$ \\
\hline A & Fácil, barato e necessário & Desireé Antônio & 41 & 2010 \\
\hline B & Água limpa de verdade & Juliana Saragá & 44 & 2011 \\
\hline C & Novos Tempos & Fabrício Marques & 46 & 2011 \\
\hline D & Radiação UV, sentinelas do clima & William Ferraz & 52 & 2013 \\
\hline E & H $_{2}$ Omem, a fórmula da & Ana Luiza Gonçalves & 54 & 2013 \\
\hline F & Energia limpa e do bem & Diogo Brito & 55 & 2013 \\
\hline G & Patrulheiras Antipoluição & Virgínia Fonseca & 56 & 2014 \\
\hline H & Cheiroso e Ecológico & Camila A. Mantovani & 58 & 2014 \\
\hline I & Cinza em tom de verde & Virgínia Fonseca & 60 & 2015 \\
\hline J & Nada se perde mesmo! & Camila A. Mantovani & 61 & 2015 \\
\hline
\end{tabular}

Fonte: Próprios autores (2020)

Os dez textos selecionados para este estudo foram analisados por meio da Análise Textual Discursiva. Essa metodologia é de natureza qualitativa, transitando entre análise de conteúdo e análise de discurso (MORAES, 2003, p.192). Segundo Moraes, a Análise Textual Discursiva,

pode ser compreendida como um processo auto-organizado de construção de compreensão em que novos entendimentos emergem de uma sequência recursiva de três componentes: desconstrução do corpus, a unitarização; o estabelecimento de relações entre os elementos unitários, a categorização; e o captar do novo emergente em que nova compreensão é comunicada e validada.

De acordo com Moraes e Galiazzi (2006, p. 132), na etapa da unitarização, os dados são desconstruídos, a partir da interpretação do pesquisador. Em nosso 
estudo, esse processo foi realizado individualmente para cada TDC selecionado, no qual fomos identificando trechos (recortes) da reportagem que constituíam unidades de análise significativas.

A segunda fase, a categorização, consiste "na organização, ordenamento e agrupamento de conjuntos de unidades de analises, no sentido de expressar novas ideias dos fenômenos investigados" (MORAES; GALIAZZI, 2006, p. 125). As categorias podem ser produzidas por métodos distintos: deduzidas das teorias que servem de fundamento para a pesquisa (categorias a priori) ou elaboradas com base nas informações contidas no corpus (categorias emergentes). Nesta pesquisa foram empregadas categorias a priori, sendo elas as considerações de Zamboni (2001) sobre características discursivas referentes aos traços de didaticidade, laicidade e cientificidade.

Com base nessas categorias discutimos as potencialidades dos TDC da revista Minas Faz Ciência para a educação em ciências, conforme apresentado a seguir.

\section{Resultados e discussão}

\section{Elementos laicos nos TDC}

A presença de características discursivas que evidenciem traços de laicidade sugere que o texto contém formas de contextualização e aproximação do leitor com a temática abordada. Essas características têm importância no contexto do ensino de ciência, uma vez que podem favorecer a relação entre o conteúdo escolar (científico) e o cotidiano do aluno.

Em nossas análises com a revista Minas Faz Ciência, verificamos que todos os TDC apresentam temática contextualizada. Ou seja, todas as reportagens que fizerem parte do corpus dessa pesquisa trouxerem discussões relacionadas a diversos contextos da vida em sociedade, evidenciando um forte traço de laicidade.

O texto $A$, por exemplo, relata um projeto concebido para atender populações de baixa renda que não têm acesso à água tratada. O lugar escolhido para o diagnóstico foi a cidade de Rio Acima, na Região Metropolitana de Belo Horizonte, banhada pelo Rio das Velhas. A pesquisa fez um levantamento do nível de escolaridade, das condições sociais e dos hábitos de higiene dos moradores, além de análises microbiológicas da água usada pelas casas e também do rio. Portanto, esse TDC favorece uma aproximação dos estudantes com problemáticas diretamente ligadas a seu contexto social.

Outro exemplo que pode ser mencionado é o texto $\mathrm{H}$, "Cheiroso e ecológico", no qual se relata um estudo sobre o desenvolvimento de sabão com propriedades medicinais a partir da reutilização do óleo de cozinha e da combinação com plantas de ação farmacológica da região de Viçosa (MG). Uma parte do texto é constituída por informações sobre a divulgação desse projeto à sociedade, além da descrição da receita do sabão, possibilitando ao leitor sua produção em casa.

Para Perticarrari et al. (2010), a presença de temáticas contextualizadas em um TDC é um critério importante para sua escolha em atividades didáticas em sala de aula. Esses autores, ao adotarem uma reportagem de jornal abordando o tema 
ecologia, observaram que o texto possibilitou múltiplas aprendizagens, uma vez que favoreceu a correlação entre conceitos científicos associados ao tema em foco e o cotidiano dos estudantes.

Santos e Schnetzler (2003) ressaltam ainda que o ensino para a cidadania não pode ser nem mesmo restrito à mera discussão ideológica do contexto social nem ao estudo de conceitos químicos descontextualizados. Ao contrário: a escola deve favorecer uma abordagem integrada de dois aspectos centrais: a informação química e o contexto social, de modo que o estudante seja capaz de perceber a influência e importância da ciência em sua vida. Dessa forma, a presença de temáticas contextualizadas nos TDC da revista Minas Faz Ciência pode favorecer, portanto, essa abordagem integrada.

Outra forma de aproximação entre o TDC e o cotidiano do leitor é por meio do impacto do lide - elemento textual no qual se destaca de forma resumida um aspecto importante da reportagem. Essa característica do discurso da divulgação científica também foi observada com frequência nos TDC, conforme mostram alguns exemplos a seguir: microcontaminantes lançados, por ação humana, nas águas da bacia do Rio Doce." (Texto E)
"Estudiosos da UFOP realizam detalhado diagnóstico dos
"Estudo atesta benefícios financeiros e ambientais da reutilização de água em aeroportos." (Texto I)
"Projeto propõe recuperação de metais nobres do lixo eletrônico para diminuir impacto ambiental e promover reuso na indústria." (Texto J)

Percebe-se, nesses exemplos, que os TDC colocam em destaque, por meio dessa característica discursiva, informações que sejam relevantes para o cotidiano do leitor, estimulando assim sua leitura.

Além do texto escrito, também foi observada em alguns dos TDC a presença da laicidade por meio de recursos visuais, os quais têm como função promover sensibilização e envolvimento do leitor com o tema abordado.

O texto $\mathrm{C}$, por exemplo, traz uma reportagem especial sobre lixo, ressaltando a capacidade produtiva dos resíduos, tipos de aparatos para captação de energia proveniente do lixo, além de assuntos relacionados aos catadores, campanha lixo zero e ainda novas perspectivas acerca da temática. Uma das imagens presentes no texto $C$ destaca a questão social relacionada aos catadores de lixo (Figura 1).

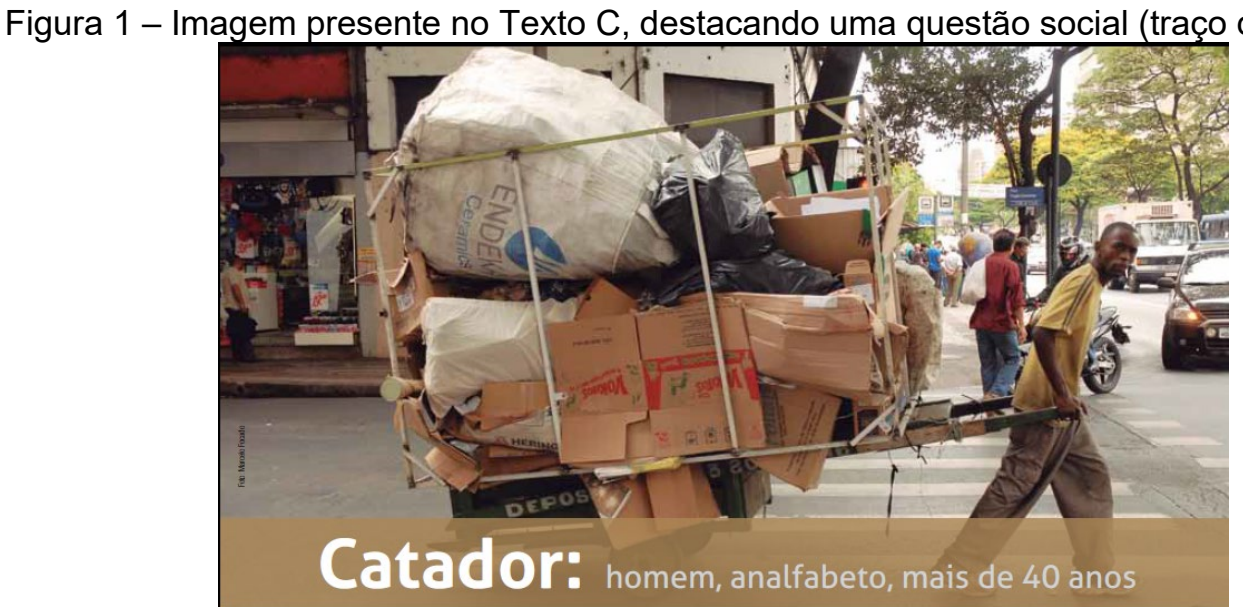

Fonte: Ferraz (2013) 
Por meio dessas características - a escolha de uma temática contextualizada, impacto do lide, recursos visuais com aspectos de laicidade - os TDC da revista Minas Faz Ciência revelam-se como um recurso potencialmente útil no sentido de promover aproximações entre o conteúdo escolar e questões sociais, ambientais, políticas e outras esferas igualmente importantes para o público em geral.

Tal fato é, de certa forma, esperado em um texto de DC para o grande público, uma vez que cada vez mais defende-se que uma de suas funções enquanto instrumento de educação não formal é proporcionar informações sobre a ciência e suas relações com a sociedade em geral, possibilitando às pessoas reconhecer os limites e possibilidades da ciência e da tecnologia no seu dia-a-dia (GOUVÊA, 2015).

Dessa forma, tais textos podem ser usados total ou parcialmente para introduzir um novo conteúdo em sala de aula ou ainda para complementar aqueles presentes no livro didático, propiciando aos alunos informações atualizadas e mais próximas de sua realidade. Podem ainda ser usados como material de suporte para debates e projetos de natureza interdisciplinar que sejam de interesse da comunidade escolar, uma vez que tais TDC colocam em destaque temas importantes dentro da sociedade contemporânea e, portanto, necessários à educação para cidadania.

\section{Elementos didáticos nos TDC}

O discurso da DC caracteriza-se pela adoração de uma série de estratégias discursivas que auxiliam o leitor não especializado em ciência na compreensão dos conteúdos expostos no texto - os aspectos de didaticidade (ZAMBONI, 2001). Nesse sentido, embora geralmente não elaborados com objetivos direcionados à educação formal, os TDC costumam apresentar uma linguagem próxima à escolar (ALMEIDA, 2010).

$\mathrm{Na}$ análise dos TDC da revista Minas Faz Ciência foi possível localizar várias estratégias dessa natureza, com destaque para os procedimentos explicativos, presentes em todos os textos. Tais procedimentos podem ser realizados por meio de definições, as quais, segundo Zamboni (2001), têm função explicativa no sentido de tornar o texto mais acessível. Esse elemento discursivo aparece em trechos nos quais conceitos científicos são definidos de forma direta no TDC:

\footnotetext{
"A radiação solar UV caracteriza-se por ondas eletromagnéticas de comprimento situado entre 280 e 400 nanômetros $\left(1 \mathrm{~nm}=10^{-9} \mathrm{~m}\right)$. Ela se subdivide em três categorias: radiação ultravioleta A (UVA, com 315 a $400 \mathrm{~nm}$ ), B (UVB, 280 a $315 \mathrm{~nm}$ ) e C (UVC, 200 a 280 nm)." (Texto D)

"O poder calorífico indica a capacidade potencial de um material desprender determinada quantidade de calor quando submetido à queima completa." (Texto C)

"Macrófitas aquáticas são plantas que, ao longo de sua evolução, retornaram do meio terrestre para o aquático. Tais espécies podem se enraizar no solo sob a água ou flutuar na superfície". (Texto G)
}

Os procedimentos explicativos também aparecem nos TDC na forma parentética (parêntesis) ou apositiva (aposto), constituindo-se elementos discursivos que fazem ruptura no texto e ajudam a intercalar aspectos científicos e explicativos para melhor entendimento do leitor, conforme ilustram alguns exemplos a seguir:

4




\begin{abstract}
"A água destilada (água pura sem sais)". (Texto B)
"Importante ressaltar, ainda, que o óleo chega intacto aos rios e às represas, fica na superfície da água e pode impedir a entrada de luz elemento que alimenta o fitoplâncton, conjunto de organismos essenciais à cadeia alimentar aquática". (Texto $\mathrm{H}$ )
\end{abstract}

Queiroz e Ferreira (2013) afirmam que os procedimentos explicativos tornam o TDC, muito próximo ao texto didático. Em suas análises com textos da revista Ciência Hoje, as autoras observaram em vários trechos a utilização de conceituações, representações química e fórmulas matemáticas - elementos típicos do discurso científico presentes na educação formal. Por essa razão, os TDC que apresentam tais características tornam-se interessantes para aplicação em sala de aula, trazendo novos conceitos ou complementando aqueles abordados no contexto escolar.

No entanto, ao se adotar um material de DC para uso no contexto escolar, devese observar se os conceitos científicos presentes em tais materiais estão corretos e adequados para o nível de ensino em que se pretende empregá-lo. No intuito de tornar alguns conceitos científicos mais facilmente compreendidos pelo leitor, alguns TDC utilizam analogias e metáforas inadequadas, as quais podem constituir obstáculos epistemológicos à construção adequada dos conceitos científicos (SILVA; TERRAZZAN, 2003).

Também foram observados elementos de didaticidade nos recursos visuais presentes em alguns dos textos analisados. Esses recursos visuais estavam expostos na forma de fotografias com a função de auxiliar na compreensão de algum procedimento usado nas pesquisas, como é o caso da imagem destacada no texto A, que mostra a estrutura de uma tubulação construída com garrafas PET (Figura 2). Em outros casos, o TDC apresentava infográficos, a fim de fornecer ao leitor algum conteúdo científico ou técnico de maneira mais clara e atrativa, conforme observado no texto I (Figura 3).

Figura 2 - Imagem presente no Texto A, explicando, por meio da fotografia da maquete, a estrutura de uma tubulação construída com garrafas PET.

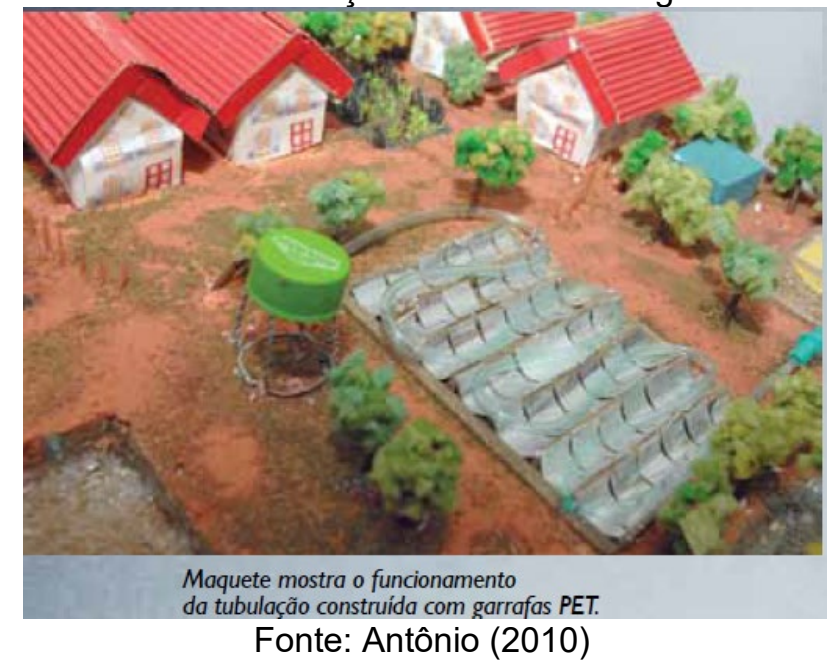


Figura 3 - Imagem presente no Texto I, apresentando por meio de infográfico as classes de qualidade para reuso da água.

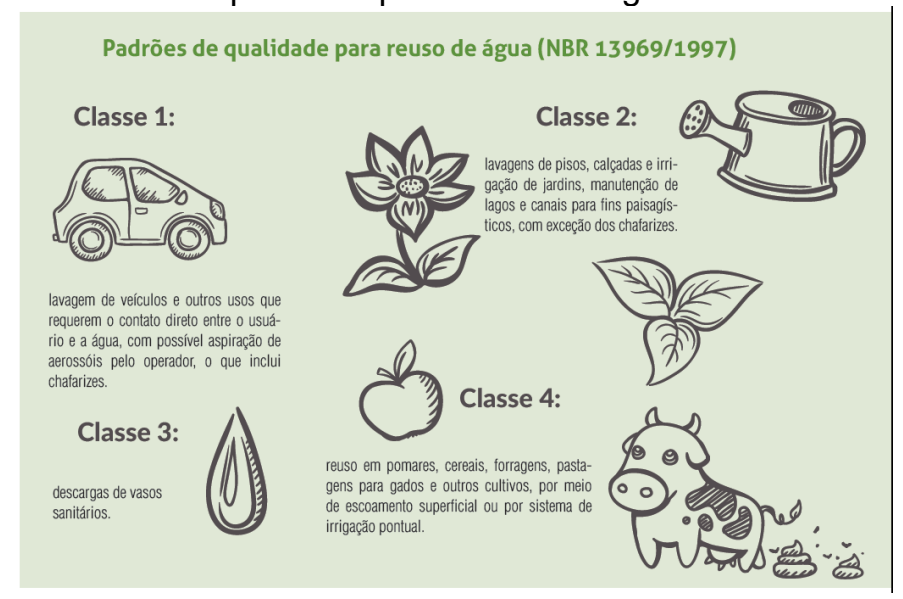

Fonte: Fonseca (2015)

Outra característica do discurso da DC que o aproxima do discurso didático é a interlocução direta com o leitor, a qual, segundo Zamboni (2001), constitui uma forma de buscar a participação ativa do interlocutor, fazendo-o compartilhar das apreciações e inquietações que o autor do texto experimenta. Essa estratégia discursiva foi observada em vários dos textos analisados, conforme revelam os seguintes trechos:

\begin{abstract}
"Algumas perguntas devem ser feitas quando da opção por geração de energia elétrica através dos RSUs: Como fica a cadeia da reciclagem? Deve-se retirar o resíduo potencialmente reciclável, o qual, geralmente, possui um PCS mais elevado? Como fica a questão do catador? É possível desenvolver um modelo de tratamento de resíduos orgânicos com viabilidade técnica e econômica de disseminação no Brasil, dando um destino correto à maior fração presente questão social, ambiental e econômica?". (Texto C)
\end{abstract}

"Contudo, o que aconteceria se esse mesmo hidrogênio fosse utilizado, como aditivo, para queima de óleo diesel?" (Texto F)

"E aí, quer produzir seu próprio sabão?" (Texto $H$ )

Nesses exemplos, é possível perceber que o autor convida o leitor a refletir sobre aspectos sociais e econômicos que envolvem o trabalho da ciência em relação à reutilização do lixo (Texto $\mathrm{C}$ ). Em outros casos, estimula-se uma análise sobre um fenômeno científico - o uso do hidrogênio na queima do óleo diesel (Texto F) ou convida-se o leitor a realizar uma ação concreta - produzir o próprio sabão (Texto $\mathrm{H})$. Em todos esses casos, o discurso do TDC assemelha-se ao do professor no intuito de conduzir o raciocínio do aprendiz pela trilha desejada ou ainda solicitar a realização de alguma tarefa. Dessa forma, a interlocução direta com o leitor observada nos TDC da revista Minas Faz Ciência confere a tais textos um potencial didático para uso em sala de aula.

Além dessas características mais pontuais, os TDC analisados apresentam diversos recursos de atratividade visual, como páginas coloridas, títulos em fontes maiores e diferentes daquelas usadas nas demais partes do texto, boxes com alguma informação em destaque etc., tornando, assim, sua leitura uma experiência sensorial mais agradável. Esses recursos gráficos também são comumente usados em livros didáticos, a fim de auxiliar o estudante no processo de leitura e identificação das informações.

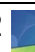


Por fim, a segmentação da informação também foi observada em vários dos TDC analisados, sobretudo na forma de boxes dando destaque a conceitos que careciam de maior explicação ou detalhamento ou de tópicos com informações independentes do restante do texto. Do ponto de vista didático, essa segmentação possibilita o acesso rápido a uma informação específica da reportagem que o professor pretenda abordar em contexto escolar, especialmente em situações nas quais ele não tenha tempo suficiente para discutir o texto em sua totalidade. Dessa forma, tal característica do discurso da DC possibilita que o TDC possa ser usado em sala de aula, ainda que parcialmente.

\title{
Elementos científicos nos TDC
}

Os TDC podem apresentar, de forma explícita ou implícita, características da linguagem da ciência e suas formas de funcionamento. Tais características podem conferir aos TDC aspectos de cientificidade e propiciar ao leitor, além de conteúdos de ciência, conhecimentos sobre a ciência.

Várias características da atividade científica, as quais, em muitos casos, representam a busca por credibilidade foram identificadas na análise dos TDC. Dentre essas, destacam-se as citações de prêmios recebidos pelos pesquisadores (Texto A) ou menção ao pioneirismo do trabalho e a geração de patentes (Texto B).

\begin{abstract}
"O diagnóstico, que compôs a primeira fase do projeto, recebeu uma série de prêmios: o $1^{\circ}$ lugar na categoria Ensino Médio do Prêmio Jovem Cientista, na edição de 2008; $2^{\mathrm{a}}$ lugar na Mostratec, uma mostra de projeto interna do Cefet, em 2007; o $3^{\circ}$ lugar na categoria Saúde na Feira Brasileira de Ciências e Engenharia (Febrace) em 2008; além do prêmio Intel ISEF (International Science and Engineering Fair, Feira Internacional de Ciência e Engenharia)." (Texto A)

"O grupo da UFVJM é o primeiro a trabalhar com essa tecnologia no País, que hoje, para utilizá-la, precisa importar. Recentemente, os pesquisadores fizeram o pedido de patente do protótipo ao Instituto Nacional da Propriedade Industrial (Inpi) tendo a FAPEMIG como cotitular da invenção". (Texto B)
\end{abstract}

Esses elementos discursivos têm a função de indicar ao leitor a relevância do estudo apresentado na reportagem. No entanto, é importante ressaltar que, se por um lado, a presença de tais aspectos nos TDC possibilita ao leitor conhecer algumas facetas da vida acadêmica - como publicações, premiações, patentes, pioneirismo -, por outro, pode causar a impressão de que a ciência é construída apenas por pesquisadores com grande destaque na comunidade científica, desconsiderando o papel de muitos outros pesquisadores cujos nomes são pouco conhecidos da sociedade em geral.

A busca de credibilidade também foi empregada nos TDC por meio da descrição de aspectos da atividade científica como: parcerias entre instituições de ensino na realização da pesquisa, participação de órgãos de fomento (Texto E) ou publicações decorrentes do estudo realizado (Texto F):

\footnotetext{
"A partir da proposta, criou-se a Rede de Monitoramento e Pesquisa das Águas do Rio Doce, que conta com intercâmbio entre a Ufop e a Universidade Federal do Espírito Santo (Ufes). Já concluído, o projeto integra uma série de investigações, iniciada em meados da década de 1990, que conta com financiamento de diversos órgãos de pesquisas, entre os quais, a FAPEMIG". (Texto E)
} 
"Além de render excelentes resultados, a pesquisa se desdobrou em cinco dissertações de mestrado, além de dois artigos em periódicos internacionais e de um sistema de injeção de hidrogênio, já em processo de patenteamento". (Texto F)

Nesses exemplos, percebe-se o uso de características do discurso da DC, como a presença do argumento de autoridade. Tal elemento tem função retórica, reforçando diante do leitor o caráter científico e a relevância da pesquisa reportada. Além disso, e talvez ainda mais importante para o contexto educativo, eles evidenciam vários aspectos da atividade científica, sejam elas implícitas ou explícitas, tais como: a importância da avaliação e reconhecimento pelos pares, a necessidade de registro e proteção do conhecimento produzido, a divulgação dentro da comunidade por meio das publicações, o trabalho em parceria entre pesquisadores e instituições, a importância dos financiamentos para o trabalho na ciência e várias outras práticas que fazem parte do cotidiano do cientista (LATOUR; WOOLGAR, 1997). Para Queiroz e Ferreira (2013), tais características presentes no discurso da divulgação científica evidenciam aspectos implícitos da atividade científica, ao mostrar a ciência como um campo multidisciplinar.

$\mathrm{Na}$ análise realizada com os TDC da revista Minas Faz Ciência, verificamos outros aspectos característicos da atividade científica, como, por exemplo, o questionamento sobre a metodologia usada na pesquisa, destacado nos trechos a seguir:

"Os testes que fizemos ainda são em escala laboratorial, precisamos realizar outros em escala-piloto. Para isso, precisamos de mais investimentos", explica. (Texto A)

"O material acabou coletado por raspagem, mas, de acordo com o pesquisador, a técnica pode ser melhorada, por exemplo, por meio da sucção". (Texto J)

A indicação de tais questões num material de DC é especialmente útil no sentido de proporcionar ao leitor uma imagem de ciência passível de falhas e não aquela que produz apenas verdades incontestáveis.

Elementos discursivos que denotam a cautela e prudência diante dos resultados indicativos de uma ciência em construção - também foram verificados alguns dos TDC da Minas Faz Ciência, conforme transcrito a seguir:

O valor do PCS obtido indica que o aproveitamento energético do RSU de $\mathrm{BH}$ pode ser viável do ponto de vista econômico, recomendando-se estudos técnicos e econômicos para comprovar tal viabilidade. (Texto $\mathrm{C}$, grifo nosso)

Recursos dessa natureza foram também identificados em TDC da revista Pesquisa FAPESP, por meio do estudo realizado por Oliveira (2017). Segundo a autora, foi possível observar em materiais dessa natureza a descrição de algumas hipóteses, dúvidas, incertezas e resultados inesperados que permearam o desenvolvimento das pesquisas.

Vale destacar que poucos dos TDC analisados neste trabalho apresentaram tais aspectos. Percebeu-se que, em geral, a revista procura dar mais ênfase aos resultados satisfatórios das pesquisas e seus benefícios para a sociedade, e pouco enfoque às limitações ou possíveis problemas delas decorrentes. Esse aspecto pode ser justificado pelo fato da revista Minas Faz Ciência ser uma publicação da FAPEMIG e ter como objetivo divulgar para o público geral os resultados decorrentes de vários projetos financiados por esta agência. No 
entanto, ao deixar de lado as limitações e falhas presentes nas pesquisas, correse o risco de proporcionar ao leitor a ideia de que a atividade científica é sempre exitosa e isenta de incertezas. Nesse sentido, é importante que o professor, ao adotar um TDC para uso no contexto escolar, possa acrescentar questões que levem os alunos a analisar de forma mais crítica as informações de ciência veiculadas nas diversas mídias. Cunha e Giordan (2015, p. 83), acrescentam ainda que

Entender o gênero da divulgação científica e analisar criticamente as publicações da divulgação da Ciência antes de levá-la à sala de aula de forma a torná-las ferramentas didáticas é tarefa do professor, pois ele é o elemento fundamental do processo.

Outro elemento de cientificidade marcante nos TDC é sua alta densidade discursiva, isto é, a presença de termos técnicos e científicos, bem como descrições de procedimentos metodológicos da pesquisa etc., conforme ilustram os trechos a seguir:

O ozônio gerado é aplicado diretamente na água que fui pelo reator, tornando possível a produção de água ultrapura para fins diversos. [...] A tecnologia comumente utilizada na Europa é denominada Corona. Nesse processo um gás seco, ar ou oxigênio puro, é submetido a uma descarga elétrica silenciosa. (Texto B)

Muitos desses termos ou conceitos são considerados conhecimentos tácitos, isto é, são termos "sobre os quais não cabe mais sujeitar a comprovação ou contestação" (ZAMBONI, 2001, p.99). Porém, observa-se dentro do discurso da divulgação científica a recuperação de conhecimentos tácitos. Alguns exemplos dessa natureza estão transcritos a seguir:

\footnotetext{
Presente em pequenas concentrações na estratosfera (parte da atmosfera que abrange aproximadamente dos 15 até 50 quilômetros de altura), o ozônio $\left(\mathrm{O}_{3}\right)$ é um gás à temperatura ambiente, instável, altamente reativo e oxidante. (Texto $\mathrm{B}$ )

Outra significativa constatação da pesquisa diz respeito aos efeitos produzidos pela presença de nebulosidade (formação de nuvens) e de aerossóis atmosféricos (dispersão de partículas de ar). (Texto D)
}

Percebe-se, portanto, que no discurso da DC a presença dos termos próprios da ciência é indispensável para que a informação científica possa chegar ao leitor. No entanto, em muitos casos, adotam-se recursos de recuperação desses conhecimentos já considerados tácitos.

Os elementos de cientificidade presentes nos TDC representam características úteis à educação em ciências. Materiais que possuam tais características podem ser usados para abordagem de vários aspectos da ciência (seus conceitos, métodos e linguagem características) e sobre ciência (as relações dentro da comunidade científica, as limitações da ciência, a busca pela credibilidade etc.).

As análises empreendidas nos textos selecionados para esta pesquisa revelaram a presença de várias características do discurso da DC que podem ser aproveitadas para distintas finalidades no contexto escolar. Conforme Queiroz e Ferreira (2013), a identificação de tais elementos discursivos pode auxiliar o professor na escolha de textos mais adequados aos seus objetivos educacionais. Quando, por exemplo, o professor desejar promover a contextualização de um determinado tema, poderá escolher um TDC que apresente um elevado grau de laicidade, ou seja, que se relacione com o cotidiano do aluno. Caso queira realizar 
trabalho direcionado ao entendimento da natureza da ciência, poderá selecionar um TDC com alto grau de cientificidade, isto é, que aborde aspectos característicos da atividade científica, sejam eles implícitos quanto explícitos. Por fim, se o professor desejar abordar predominantemente conceitos científicos, em uma linguagem acessível e com recursos didáticos atrativos, poderá adotar TDC com alto grau de didaticidade.

\section{Considerações finais}

Considerando a importância do TDC para a educação em ciências e a necessidade de trabalhos que busquem avaliar o potencial didático do mesmo, nossa pesquisa fundamentou-se na análise das características discursivas e nas potencialidades didáticas de textos de divulgação científica publicados na revista Minas Faz Ciência, uma revista de divulgação científica produzida por uma agência de apoio à pesquisa - a FAPEMIG. A análise geral dos textos revelou que os aspectos de didaticidade, laicidade e cientificidade estão fortemente presentes nessa revista. Esse dado é importante no sentido de apontar algumas possibilidades de uso desse material no contexto educacional.

A presença de aspectos de didaticidade - como o amplo uso de uso de procedimentos explicativos, bem como elementos gráficos com características didáticas - indica que tais textos possam ser usados em sala de aula para se trabalhar objetivos conceituais, explorando as definições de alguns conceitos específicos da ciência e/ou complementando informações presentes nos livros didáticos sobre um mesmo tema.

Já a presença de laicidade permite que os textos dessa revista possam se aproximar da escola promovendo uma contextualização do ensino, uma vez que eles trazem para sala de aula questões atuais e pertinentes ao contexto social do educando. Textos com tais características podem ser usados, por exemplo, para introduzir um tema ou estimular seu estudo ainda fomentar o desenvolvimento de um projeto na escola que esteja articulado com o cotidiano do aluno.

Os aspectos de cientificidade, embora menos frequentes nos TDC, possibilitam abordar ainda questões relacionadas aos métodos usados na ciência, o trabalho do cientista e as relações presentes dentro da comunidade científica. Essas questões ainda são pouco exploradas nas aulas de ciência. Dessa forma, reconhecemos que alguns textos dessa revista possam se constituir em um recurso para abordagem da prática da ciência em sala de aula, favorecendo a desmistificação de algumas ideias inadequadas ou caricaturadas sobre a ciência.

Muitos desses elementos discursivos, observados nesta pesquisa e apontados como útil ao ensino de ciências, não estão colocados pelos autores de forma muito explícita nos TDC e nem são facilmente identificados pelos leitores em geral. A notícia final e sua implicação direta na sociedade costuma ser o elemento que mais chama a atenção do leitor. Dessa forma, ao ser transposto para a sala de aula, é importante que o professor conduza a leitura e discussões, apontando, quando necessário, os aspectos que considera relevante de acordo com os objetivos didáticos previamente adotados.

Por fim, é importante lembrar que os TDC da revista Minas Faz Ciência - assim como muitos outros oriundos de agências de fomento à pesquisa - adotam estratégias discursivas que ressaltam de forma considerável os resultados de

L


sucesso das pesquisas e mérito dos pesquisadores. Esse fato pode vir a propiciar a imagem de que a ciência sempre produz resultados exitosos e úteis à sociedade ou ainda que os pesquisadores são somente aqueles que obtêm destaque entre seus pares. Ainda que tais aspectos não anulem o potencial didático de tais textos, conforme revelaram as análises mostradas anteriormente, salientamos a necessidade de que essas questões sejam abordadas pelo professor, no contexto de leitura e discussão desse material.

\section{Referências}

ALBAGLI, S. Divulgação científica: informação para a cidadania? Revista Ciência da Informação, v. 25, n. 3, p. 396-404, 1996.

ALMEIDA, M. J. P. M. de. O texto de divulgação científica como recurso didático na mediação do discurso escolar relativo à Ciência. In: PINTO, G. A. Divulgação científica e práticas educativas. Curitiba: Editora CRV, 2010.

BUENO, W. C. Comunicação cientifica e divulgação científica: aproximações e rupturas conceituais. Informação \& Informação, v. 15, n. Esp., p. 1-12, 2010.

CHAVES, T. V.; MEZOMMO, J.; TERRAZAN, A. Textos de divulgação científica como recurso didático para o ensino-aprendizagem da física clássica: exemplos em termodinâmica e eletromagnetismo. In: ENCONTRO NACIONAL DE PESQUISA DE EDUCAÇÃO EM CIÊNCIAS, 3, 2001. Atas... Atibaia, ABRAPEC, 2001.

CUNHA, M. B.; GIORDAN, M. A divulgação científica em sala de aula: implicações de um gênero. In: GIORDAN, M.; CUNHA, M;B. (orgs). Divulgação científica na sala de aula: perspectivas e possibilidades. ljuí: Editora Unijuí, 2015. p.67-85.

FAPEMIG. Minas Faz Ciência. Disponível em: < http://www.fapemig.br/ptbr/minas-faz-ciencia>. Acesso em: 10 maio 2018.

FERREIRA, L. N. A.; QUEIROZ, S. L. Texto de divulgação científica no ensino de ciências: uma revisão. Revista Alexandria, v. 5, n. 1, p. 3-31, 2012.

FOSSEY, M. F. A semântica global em duas revistas de divulgação científica: pesquisa FAPESP e SUPERINTERESSANTE. Revista dos Cursos de PósGraduação, v. 12, p.129-143, 2007.

GABANA, M.; LUNARDI, G.; TERRAZZAN, E. A. Textos de divulgação científica: avaliando uma estratégia didática para o ensino médio. In: ENCONTRO NACIONAL DE PESQUISA EM EDUCAÇÃO EM CIÊNCIAS, 4, 2003, Bauru. Atas...Bauru, 2003.

GONTIJO, G. B.; OLIVEIRA, J. R. S. O texto de divulgação científica na abordagem da sociologia da ciência: um estudo da revista Minas Faz Ciência. Revista Dynamis, v.25, n.2, p.152-172, 2019.

GOUVÊA, G. A divulgação da ciência, da técnica e cidadania e a sala de aula. In: GIORDAN, M.; CUNHA, M;B. (orgs). Divulgação científica na sala de aula: perspectivas e possibilidades. Ijuí: Editora Unijuí, 2015. p.13-41.

LATOUR, B.; WOOLGAR, S. A vida de laboratório: a produção dos fatos científicos. Rio de Janeiro: Relume Dumará, 1997. 
MARTINS, I.; NASCIMENTO, T. G.; ABREU, T. B. Clonagem na sala de aula: um exemplo do uso didático de um texto de divulgação científica. Investigações em ensino de Ciências, v. 9, n. 1, p. 95-111, 2004.

MORAES, R. Uma tempestade de luz: A compreensão possibilitada pela análise textual discursiva. Ciência \&Educação, v.9, n.2, p.191-211, 2003.

MORAES, R; GALIAZZI, M. C. Análise textual discursiva: processo construído de múltiplas faces. Ciência \& Educação, v.12, n.1, p.117-128, 2006.

MOTA, G. P. R.; GONTIJO, G. B.; OLIVEIRA, J. R. S. A Revista "Pesquisa FAPESP" como Recurso para Abordagem da Sociologia da Ciência. Revista Brasileira de Pesquisa em Educação em Ciências, v. 17, n. 3, p. 953-983, 2017.

OCÁRIZ, I. C. Análise das cartas do leitor de duas revistas jornalísticas de divulgação. 2013. 132p. Dissertação (Mestrado em Divulgação Científica) Universidade Estadual de Campinas, Campinas, SP, 2013.

OLIVEIRA, J. R. S. Aspectos da sociologia da ciência em textos de divulgação científica da revista Pesquisa FAPESP. Revista Ciências \& Ideias, v.8, n.3, p.4563, 2017.

PERTICARRARI, A.; TRIGO, F. R.; BARBIERI, M. R.; COVAS, D. T. O uso de texto de divulgação científica para o ensino de conceitos sobre ecologia a estudantes da educação básica. Ciência \& Educação, v. 16, n. 2, p. 369-386, 2010.

QUEIROZ, S. L.; FERREIRA, L. N. A. Traços de cientificidade, didaticidade e laicidade em artigos da revista "Ciência Hoje" relacionados à química. Ciência \& Educação, v. 19, n. 4, p. 947-969, 2013.

SANTOS, W. L. P. SCHNETZLER, R. P. Educação em Química: compromisso com a cidadania. 3 ed. ljuí: Editora Unijuí, 2003.

SILVA, A. C.; ALMEIDA, M. J. P. M. O deslocamento de aspectos do funcionamento do discurso pedagógico pela leitura de textos de divulgação científica em aulas de Física. Revista Electrónica de Enseñanza de lãs Ciências, v. 4, n. 3, p. 1-25, 2005.

SILVA, L. L.; TERRAZZAN, E. A. As analogias na divulgação científica: o caso da Ciência Hoje das Crianças. In: Encontro Nacional de Pesquisa em Educação em Ciências, 4. 2003, Bauru. Atas... Bauru, 2003.

TARGINO, M. G. Divulgação científica e discurso. Comunicação \& Inovação, v. 8, n. 15, p.19-28, 2007.

ZAMBONI, L. M. S. Cientistas, jornalistas e a divulgação científica: subjetividade e heterogeneidade no discurso da divulgação científica. Campinas: Autores Associados, 2001. 
Recebido: $08 / 0420$

Aprovado: $07 / 05 / 20$

Como citar: BATISTELE, M. C. B.; OLIVEIRA, J. R. S. Características discursivas de textos da revista Minas Faz Ciência e suas potencialidades no ensino de química. Revista de Estudos e Pesquisa sobre Ensino Tecnológico (EDUCITEC), v. 6, e124720, 2020.

Direito autoral: Este artigo está licenciado sob os termos da Licença Creative CommonsAtribuição 4.0 Internacional.

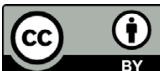

